\title{
Outcomes in Thoracolumbar and Lumbar Traumatic Fractures: Does Restoration of Unfused Segmental Mobility Correlated to Implant Removal Time欧a retrospective study
}

\section{Jian Wu}

Daping hospital of Army Medical University

Jun Zhu

Daping hospital of Army Medical University

\section{Zhong Wang}

Daping hospital of Army Medical University

Huaijian Jin

Daping hospital of Army Medical University

\section{Yingbo Wang}

Daping hospital of Army Medical University

Baiyi Liu

Daping hospital of Army Medical University

\section{Xiang Yin}

Daping hospital of Army Medical University

\section{Longbin Du}

Daping hospital of Army Medical University

\section{Yu Wang}

Daping hospital of Army Medical University

\section{Mingyong Liu}

Daping hospital of Army Medical University

Peng Liu ( $\sim$ liupengd@163.com )

Army Medical University https://orcid.org/0000-0002-6678-2266

\section{Research article}

Keywords: Lumbar vertebrae, thoracic vertebrae, fracture fixation, device removal, range of motion, quality of life

Posted Date: January 29th, 2021 
DOI: https://doi.org/10.21203/rs.3.rs-157715/v1

License: (c) (1) This work is licensed under a Creative Commons Attribution 4.0 International License. Read Full License 


\section{Abstract \\ Background}

Posterior fixation without fusion can treat thoracolumbar and lumbar traumatic fractures effectively. However, whether patients benefit from implant removal, as well as the correlation between the range of motion (ROM) of the involved segments and the removal time, has not been determined.

\section{Methods}

Fifty consecutive cases with thoracolumbar traumatic fractures that had undergone implant removal at different times were enrolled. We found 17 patients (Group A), 21 patients (Group B), and 12 patients (Group C) underwent implant removal following the index surgery within 12 months, between 12 to 24 months, and over 24 months, respectively. Clinical and radiological outcomes, including visual analog scale (VAS) for back pain, patient satisfaction, the Oswestry disability index (ODI) and EuroQol five dimensions questionnaire (EQ-5D) for quality of life and segmental ROM were analyzed.

\section{Results}

The average follow-up time was $9.1 \pm 5.7$ months after implant removal. There were no significant differences in VAS and patient satisfaction among the three groups at the same observation time points. Patients of group A gained the lowest ODI and highest EQ-5D scores after removal and at final follow-up than those in group B and C. The best ROM was obtained in Group A followed by Group B and C (11.5 \pm $6.2^{\circ}, 5.5 \pm 1.6^{\circ}$ and $2.4 \pm 0.6^{\circ}$, respectively).

\section{Conclusions}

Immobilization of the involved segments over 24 months may lead to ankylosis. Regained segmental ROM is correlated negatively with implant removal time. Patients have implant removal within 12 months can gain a better quality of life.

\section{Background}

The increasing incidence of traumatic fractures in the thoracolumbar and lumbar region, especially among the young and middle-aged populations, has become a major cause of hospitalization and disability. Surgical treatment is the most frequently employed method in such patients for providing greater initial stability and for regaining normal sagittal alignment ${ }^{1}$.

In recent decades, posterior pedicle screw fixation without fusion was proven to be as effective as fusion surgery $^{2,3}$. Theoretically, such nonfusion surgery may preserve the normal spine structure after implant 
removal compared to fixation with intersegmental fusion. In addition, given the possibility of implant failure attributed to long term fretting wear of nonfusion segments, all implants should be removed if fusion is not conducted. Previous studies mainly focused on the necessity of implant removal because of the potential hazards, such as symptomatic misplacement, implant breakage or loosening ${ }^{4}$. Several studies concentrated on improving clinical outcomes, such as back pain and quality of life $e^{4-6}$. Other cohort retrospective studies with limited samples described that the range of motion (ROM) of the fixed segments could be regained after implant removal ${ }^{6}$. Nevertheless, to our knowledge, no consensus has been reached on the correlation between outcomes and implant removal time.

The present study aimed to evaluate the clinical and radiological outcomes of patients following implant removal at different times and to identify the proper removal time that benefits patients most.

\section{Material And Methods}

The study was approved by the ethics committee of the Army Medical Center of PLA (IRB approval number: 2019120) and was conducted according to the principles of the Declaration of Helsinki. In addition, it was registered in the Clinical Trial Registry (ChiCTR) with no. ChiCTR1900028097.

\section{Study subjects}

From January 2018 to October 2020, 50 consecutive patients who underwent implant removal following successful posterior fixation without fusion for thoracolumbar and lumbar traumatic fractures in our institute were enrolled in this study. All surgeries were performed by experienced senior surgeons at our institute.

Inclusion criteria: (1) patients underwent implant removal following posterior fixation surgery without fusion; and (2) bony healing of the fractured vertebrae was assessed by a computed tomographic (CT) scan before removal; and (3) complete clinical and radiological data were available. Exclusion criteria: (1) involving fractures above T10; or (2) complicating with other dysfunctions that affected spine mobility and clinical outcomes, such as ankylosing spondylitis, untreated severe osteoporosis and so on; or (3) a deep surgical site infection; or (4) a neurological deficit.

Fifty patients were divided into three groups based on the removal time after index surgery. The removal time was defined as the time interval between the fixation and the removal surgery. Patients who underwent implant removal within 12 months (mean: 10.6 months, range: 8.8 to 11.9 months) were enrolled into Group A ( $n=17)$, patients between 12 and 24 months (mean: 17.9 months, range: 13.0 to 23.6 months) were enrolled into Group $B(n=21)$, and patients with removal after 24 months (mean: 32.8 months, range: 24.1 to 67.1 months) were enrolled into Group $C(n=12)$.

Patients' data collected at the time before removal surgery, including age, sex, body mass index (BMI), smoking status, injury and operation related information were obtained from medical documents and through interviews. 


\section{Clinical outcomes assessment}

The clinical outcomes were assessed by a visual analog scale (VAS) ${ }^{7}$ for back pain, the Oswestry disability index (ODI) ${ }^{8}$ and EuroQol five dimensions questionnaire (EQ-5D) for quality of life and patient satisfaction ${ }^{9}$ were compared among the three groups at the timepoints of preremoval, postremoval and

final follow-up. The EQ-5D questionnaire focused on patients' opinion concerning experienced benefit and satisfaction gained at the final follow-up. These were answered on a three-level scale (a lot, some or none), and the first two answers were seemed as problem while the last as no problem.

\section{Radiological Findings Assessment}

From lateral standing radiographs, the Cobb angle of the fixed segments was defined as the angle between the superior end plate of the upper instrumented vertebra and the inferior endplate of the lower instrumented vertebra ${ }^{4}$. Specifically, total ROM of the fixed segments was identified on flexion-extension radiographs at final follow-up ${ }^{10}$ (Fig. 1), and ROM per level was calculated through the total ROM divided by the number of fixed levels. In addition, the percentage of regained ROM per level to the normal one was calculated. The normal ROM from $\mathrm{T} 10$ to $\mathrm{S} 1$ was $9^{\circ}, 12^{\circ}, 12^{\circ}, 12^{\circ}, 14^{\circ}, 15^{\circ}, 17^{\circ}$ and $20^{\circ}$ respectively ${ }^{11}$. All measures were conducted three times one week apart by three independent researchers who were unaware of the implant removal time, and their inter- and intraobserver correlation coefficients were calculated. The average of the values was used as the final one.

\section{Statistical Analysis}

All statistical analysis was performed using SPSS software version 21.0 (IBM Corp., Armonk, NY). Categorical data are presented by frequencies (percentages) and analyzed by the Pearson chi-square test and Fisher exact probability test among the three groups. Continuous data were presented as the mean \pm standard deviation (SD) and analyzed by one-way analysis and the least significant difference (LSD) test was used for pairwise comparisons. The intra- and interclass correlation coefficient (ICC) statistics were used to evaluate the consistency of the Cobb angles measured among the three surgeons. The repeated measures analysis of variance test was used to explore whether the VAS, ODI and Cobb angle had changed with time. Differences were deemed statistically significant when $P$ values were less than 0.05 .

\section{Results}

\section{Patients' general information}

All patients underwent implant removal successfully, and no severe operation-related complications occurred. Minor complications included screw breakage in two patients of group $B$, and poor incision healing in two of group B and one of group C, but all of these patients eventually healed without sequelae. The demographics, injury and surgery-related information of three groups are shown in Table 1. 
There was no significant difference in any of the baseline data among the three groups (all $P>0.05$ ). The mean follow-up time was $9.1 \pm 5.7$ months.

\section{Clinical outcomes}

The mean VAS for back pain was decreased significantly after implant removal (all $P<0.05$ ) and maintained at the final follow-up, but with no significant differences among the three groups at the same time points (all $P>0.05$ ). Patient satisfaction among the three groups showed no significant difference $(P>0.05)$. The mean ODI declined significantly after removal (all $P<0.05)$ and was maintained until the final follow-up in all three groups. Furthermore, the ODI of group A was lower than that of group $C(P<$ $0.05)$, but similar to group $\mathrm{B}(P>0.05)$ after removal and at final follow-up. The mean EQ-5D scores increased significantly after removal (all $P<0.05$ ) and was maintained until the final follow-up in group A and $\mathrm{B}$ (both $P<.0001)$, but remained almost unchanged in group $\mathrm{C}(P>0.05)$. Furthermore, the ODI of group A was lower than that of group $C(P<0.05)$, and EQ-5D scores of group A was higher than that of group $B$ and $C$ after removal and at final follow-up (both $P<0.05$ ) (Table 2). Among the EQ-5D questionnaire, patients of group A showed the lowest proportion of problems in all dimensions except for self-care (Fig. 2).

\section{Radiological findings}

A reliability analysis showed that the interobserver consistency among the observers in measuring the Cobb angle of these 50 patients was very good, with an ICC value of at least 0.970 . After removal of the implants, the Cobb angle increased by $5.0^{\circ}$ to $8.6^{\circ}$ on average at final follow-up, but the difference between postfixation and the final follow-up of the three groups showed no significant difference (group A, $5.0 \pm 2.4^{\circ}$, group $B, 8.5 \pm 7.1^{\circ}$, group $\left.C, 8.6 \pm 4.2^{\circ}, P>0.05\right)$. Both total segmental ROM and ROM per level in group $A$ were significantly greater than that of group $B$ and $C(P<0.05)$, while those in group $B$ were greater than in group $\mathrm{C}(P<0.05)$ (Table 3$)$.

\section{Discussion}

The result of the present study suggest implant removal is beneficial to clinical and radiological outcomes for patients treated successfully for thoracolumbar traumatic fractures, and the outcomes were negatively correlated with the time of removal. Patients subjected to implant removal within 12 months could obtain better clinical outcomes, especially in ODI and EQ-5D, and patients subjected to implant removal within 12 months could also regain greater ROM of the fixed segments.

Posterior short-segment fixation surgery with pedicle screws has become the most widely used method to repair traumatic spine fractures since it was first introduced in the $1980 \mathrm{~s}^{12}$. Kim et al. ${ }^{13}$ has suggested that a nonfusion method appears to also be effective in achieving favorable sagittal alignment with a shorter operative time and less blood loss. This unfused method has also been confirmed by prospective studies $^{14}$ and meta-analyses and systematic reviews in recent years ${ }^{15,16}$. 
Considering the disadvantages of leaving the implants in situ, such as back pain, functional impairments and implant-induced injury to the spine ${ }^{17-19}$, implant removal following nonfusion surgery seems beneficial. Although implant removal surgery has been widely used especially among nonfused patients in recent years, the literature has reported conflicting results following implant removal because of heterogeneity in the patients' demographics and surgical objectives.

Jeon et al. ${ }^{10}$ reported 45 patients with implant removal and 45 age- and gender-matched patients with implant retainment after being successfully treated for thoracolumbar (T11-L2) burst fractures. Both the mean VAS for back pain and the mean ODI in the implant removal group were significantly lower than those in the control group at the 1-year and 2-year follow-up. In addition, the segmental ROM of the implant removal group increased significantly at the 1-year follow-up, but no obvious difference was found in the control group.

As for clinical outcomes, similar to Jeon, the present study showed that implant removal had high patient satisfaction and benefited patients in regard to VAS, ODI and EQ-5D regardless of removal time. The exact mechanism is still unclear but may involve the local microenvironments, metallic properties, surgical site infections or allergic reactions that can cause implant-related pain ${ }^{20-22}$. It was certain that the back pain caused by the irritation of the internal fixation can be relieved through removing the implant, and the quality of life is consequently improved.

It might be an interesting observation in this work that different removal times had little impact on patients' back pain, but they did on ODI. Patients who underwent implant removal after 24 months showed undesired recovery of ODI and EQ-5D compared to those with an earlier removal. We analyzed the reason for the high ODI level further, and found such patients generally exhibited easy muscle fatigue.

Recurrent kyphosis after implant removal has always been a major concern for surgeons. In a study by Lindsey et al. ${ }^{23}, 80$ patients with thoracolumbar fracture were analyzed, and a mean postoperative kyphosis of $6^{\circ}$ became a kyphosis of $9.5^{\circ}$ one year after surgery. Kanezaki ${ }^{24}$ also reported the median local kyphosis angle correction loss was $9^{\circ}$ and concluded that the kyphosis changes occurred mainly at the intervertebral disc level, rather than at the site of the vertebral body. Similar to these papers, our study showed a recurrent kyphosis of the involved segmental as well (range from $5.0^{\circ}$ to $8.6^{\circ}$ on average), but no obvious correlation between increased kyphosis and implant removal time was seen.

As for ROM of the fixed vertebral segments, studies ${ }^{10,17,18}$ have shown that implant removal could regain it. Ko et al. observed 60 patients who received posterior fixation without fusion for thoracolumbar and lumbar fractures (T11-L3), and then they underwent implant removal at a mean time of 12.2 months. They concluded that, based on 38 months of follow-up after implant removal, the total mean ROM was $9.12^{\circ 25}$. In addition, Jeon et al. ${ }^{10}$ studied 45 cases with thoracolumbar fractures (T11-L2) treated by longsegment instrumentation (4.4 levels on average) with short-segment fusion ( 1.2 levels on average). The time from index fracture surgery to implant removal was 18.3 months on average. They found that the 
mean segmental motion angle was $1.6^{\circ}$ at the time of removal, which increased to $5.8^{\circ}$ at the 1 -year follow-up and was maintained until the 2-year follow-up.

Based on our study covering the whole course of treatment, we concluded that patients with thoracolumbar fractures (T11-L3) in group A can achieve a functional segmental ROM $11.5^{\circ}$ on average and restore $41.6 \%$ of the normal value, which is in accordance with Ko's findings. Meanwhile, the average ROM in group B was close to Jeon's findings and did little to improve spinal mobility. In addition, our results demonstrated that the ROM in group $C$ was significantly smaller, which was equivalent immobility. We concluded that the restored segmental ROM correlated with removal time and that prolonged fixation leads ROM to be unrecoverable, but this might not be caused by intervertebral fusion. Gardener and Armstrong ${ }^{26}$ found spontaneous fusion in only two of 75 facet joints after instrumentation without fusion. They also reported that $33.3 \%$ of nonfused temporarily fixed lumbar facet joints became sclerotic when implants were removed at 18.3 months after surgery on average. Meanwhile, no spontaneous fusion of facet joints and no bony bridge formation between vertebrae in this study were seen under CT before removal. Therefore, we speculate the reduced segmental ROM was caused by spontaneous stiffness of the facet joints resulting from prolonged immobilization of the fixed segments.

\section{Limitations}

Several limitations of the present study should be considered: (1) This study was a retrospective cohort with a relative low evidence level; (2) Patients in this study were grouped by year. As we know, there are four bone remodeling cycles per year. An optimal removal time shorter than 12 months may exist. A prospective study is necessary to identify whether a shorter time interval than 12 months would address this issue.

\section{Conclusions}

For patients treated successfully for thoracolumbar traumatic fractures, implant removal following vertebral fracture healing can preserve the injured segmental ROM, and it is negatively related to the removal time. Implant removal performed within 12 months could achieve better functional spinal mobility and favorable quality of life, and for patients with instrumentation retained for 24 months or more, implant removal provides fewer benefits.

\section{Abbreviations}

ROM: range of motion; VAS: visual analog scale; ODI: Oswestry disability index; EQ-5D: EuroQol five dimensions questionnaire; BMI: body mass index

\section{Declarations}

Acknowledgements 
Not applicable

\section{Authors' contributions}

$\mathrm{PL}$ and $\mathrm{ML}$ designed the study and performed the surgery; JW, JZ, and ZW performed the study and interpretation; $H J, Y W$, and $B L$ contributed in writing the manuscript; $X Y, L D$ and $Y W$ assisted with the statistical analysis. All authors read and approved the final manuscript.

\section{Funding}

The author(s) disclosed receipt of the following financial support for the research, authorship, and/or publication of this article: this study was funded by the Army Medical University Project of Medical Elite Training (2018XLC2024 and 2019CXLCB015).

\section{Availability of data and materials}

The data and materials might be obtained from the corresponding author unpon request.

\section{Ethics approval and consent to participate}

The study was approved by the ethics committee of the Army Medical Center of PLA, Chongqing, China (ethical review number: 2019120) and was registered in the Clinical Trial Registry (ChiCTR) with no. ChiCTR1900028097.

\section{Consent for publication}

Not applicable

\section{Competing interests}

The authors declare that they have no competing interests.

\section{References}

1. Wood KB, Li W, Lebl DR, et al. Management of thoracolumbar spine fractures. Spine J 2014;14:14564.

2. Mayer HM, Korge A. Non-fusion technology in degenerative lumbar spinal disorders: facts, questions, challenges. Eur Spine J 2002;11 (suppl 2):S85-91.

3. Panjabi MM. Hybrid multidirectional test method to evaluate spinal adjacent-level effects. Clin Biomech (Bristol, Avon) 2007;22:257-65.

4. Chou PH, Ma HL, Liu CL, et al. Is removal of the implants needed after fixation of burst fractures of the thoracolumbar and lumbar spine without fusion? a retrospective evaluation of radiological and functional outcomes. Bone Joint J 2016;98:109-16. 
5. Jentzsch T, Gomes de Lima V, Seifert B, et al. The benefits of elective spinal implant removal: a retrospective study of 137 patients. Eur Spine J 2016;25:856-64.

6. Axelsson P, Strömqvist B. Can implant removal restore mobility after fracture of the thoracolumbar segment? Acta Orthop 2016;87:511-5.

7. Huskisson EC. Measurement of pain. Lancet 1974;2:1127-31.

8. Fairbank JC, Pynsent PB. The oswestry disability index. Spine (Phila Pa 1976) 2000;25:2940-52.

9. Molinari RW, Khera OA, Gruhn WL, et al. Rigid cervical collar treatment for geriatric type II odontoid fractures. Eur Spine J 2012;21:855-62.

10. Jeon $\mathrm{CH}$, Lee HD, Lee YS, et al. Is It beneficial to remove the pedicle screw instrument after successful posterior fusion of thoracolumbar burst fractures? Spine (Phila Pa 1976) 2015;40:E627E633.

11. Prévost MA, McGuire RA, Garfin SR, et al. Thoracic and upper lumbar spine injuries thoracic and upper lumbar spine injuries. In: Brown BD ed. Skeletal Trauma: Basic Science, Management, and Reconstruction (3rd). Philadelphia, Pennsylvania, FL: Saunders Press; 2003:898-966.

12. 12. Olerud S, Karlstrom G, Sjöström L. Transpedicular fixation of thoracolumbar vertebral fractures. Clin Orthop 1988;227:44-51.

13. 13. Kim YM, Kim DS, Choi ES, et al. Nonfusion method in thoracolumbar and lumbar spinal fractures. Spine (Phila Pa 1976) 2011;36:170-6.

14. 14. Kim HY, Kim HS, Kim SW, et al. Short segment screw fixation without fusion for unstable thoracolumbar and lumbar burst fracture: A prospective study on selective consecutive patients. $\mathrm{J}$ Korean Neurosurg Soc 2012;51:203-7.

15. 15. Tian NF, Wu YS, Zhang XL, et al. Fusion versus nonfusion for surgically treated thoracolumbar burst fractures: a meta-analysis. PLoS One 2013;8:e63995.

16. 16. Lan T, Chen Y, Hu SY, et al. Is fusion superior to non-fusion for the treatment of thoracolumbar burst fracture? A systematic review and meta-analysis. J Orthop Sci 2017;22:828-833.

17. 17. Smits AJ, den Ouden $L$, Jonkergouw $A$, et al. Posterior implant removal in patients with thoracolumbar spine fractures: long-term results. Eur Spine J 2017;26:1525-1534.

18. Kim HS, Kim SW, Ju Cl, et al. Implant removal after percutaneous short segment fixation for thoracolumbar burst fracture: does it preserve motion? J Korean Neurosurg Soc 2014;55:73-7.

19. Butt MF, Farooq M, Mir B, et al. Management of unstable thoracolumbar spinal injuries by posterior short segment spinal fixation. Int Orthop 2007;31:259-264.

20. Jamil W, Allami M, Choudhury MZ, et al. Do orthopaedic surgeons need a policy on the removal of metalwork? A descriptive national survey of practicing surgeons in the United Kingdom. Injury 2008;39:362-7.

21. Kim HJ, Chun HJ, Moon SH, et al. Analysis of biomechanical changes after removal of instrumentation in lumbar arthrodesis by finite element analysis. Medical \& biological engineering \& computing 2010;48:703-9. 
22. Kim HJ, Kang KT, Moon SH, et al. The quantitative assessment of risk factors to overstress at adjacent segments after lumar fusion: removal of posterior ligaments and pedicle screws. Spine (Phila Pa 1976) 2010;48:703-9.

23. Lindsey RW, Dick W, Nunchuck S, et al. Residual intersegmental spinal mobility following limited pedicle fixation of thoracolumbar spine fractures with the fixateur interne. Spine (Phila Pa 1976) 1993;18:474-8.

24. Kanezaki S, Miyazaki M, Ishihara T, et al. Magnetic resonance imaging evaluation of intervertebral disc injuries can predict kyphotic deformity after posterior fixation of unstable thoracolumbar spine injuries. Medicine (Baltimore) 2018;97:e11442.

25. Ko SB, Lee SW. Result of posterior instrumentation without fusion in the management of thoracolumbar and lumbar unstable burst fracture. J Spinal Disord Tech 2014;27:189-195.

26. Gardner VO, Armstrong GW. Long-term lumbar facet joint changes in spinal fracture patients treated with Harrington rods. Spine 1990;15:479-84.

\section{Tables}

Table 1. Demographics, Injury and Surgery Related Information

\begin{tabular}{|c|c|c|c|c|}
\hline Variable & $\begin{array}{c}\text { Group A } \\
(\mathrm{n}=17)\end{array}$ & $\begin{array}{c}\text { Group B } \\
(\mathrm{n}=21)\end{array}$ & $\begin{array}{c}\text { Group C } \\
(\mathrm{n}=12)\end{array}$ & $P$ \\
\hline$\overline{\text { Age }(y, \text { mean } \pm S D)}$ & $42.7 \pm 10.6$ & $45.6 \pm 10.1$ & $38.8 \pm 10.7$ & NS \\
\hline Male (n, \%) & $10(58.82)$ & $14(66.67)$ & $5(41.67)$ & NS \\
\hline BMI $\left(\mathrm{Kg} / \mathrm{m}^{2}\right.$, mean $\left.\pm \mathrm{SD}\right)$ & $22.2 \pm 3.2$ & $23.6 \pm 2.8$ & $24.5 \pm 3.5$ & NS \\
\hline Current smoker (n, \%) & $3(17.65)$ & $5(23.81)$ & 0 & NS \\
\hline Injury mechanism $(\mathrm{n}, \%)$ & & & & NS \\
\hline Fall from height & $15(88.24)$ & $18(85.71)$ & $6(50.00)$ & \\
\hline Traffic accident & $2(11.76)$ & $2(9.53)$ & $3(25.00)$ & \\
\hline Others & 0 & $1(4.76)$ & $3(25.00)$ & \\
\hline Number of fractured vertebral bodies (n, \% & & & & NS \\
\hline single & $17(100)$ & $16(76.19)$ & 11 (91.67) & \\
\hline multiple & 0 & $5(23.81)$ & $1(8.33)$ & \\
\hline Fractured vertebra (n, \%) & & & & NS \\
\hline T10-L2 & $16(94.12)$ & $13(61.90)$ & $9(75.00)$ & \\
\hline L3-L5 & $1(5.88)$ & $8(36.10)$ & $3(25.00)$ & \\
\hline Number of fixation segments (n, \%) & & & & NS \\
\hline 2 & $17(100)$ & $15(71.43)$ & 11 (91.67) & \\
\hline 3 & 0 & $5(23.81)$ & 0 & \\
\hline 4 & 0 & $1(4.76)$ & $1(8.33)$ & \\
\hline mean & 2.00 & 2.38 & 2.17 & \\
\hline Surgery time (days after injury, mean \pm SD) & $4.1 \pm 2.7$ & $5.0 \pm 2.4$ & $6.4 \pm 2.8$ & NS \\
\hline
\end{tabular}


Table 2. VAS scores for back pain, patient satisfaction, ODI and EQ-5D scores for life quality

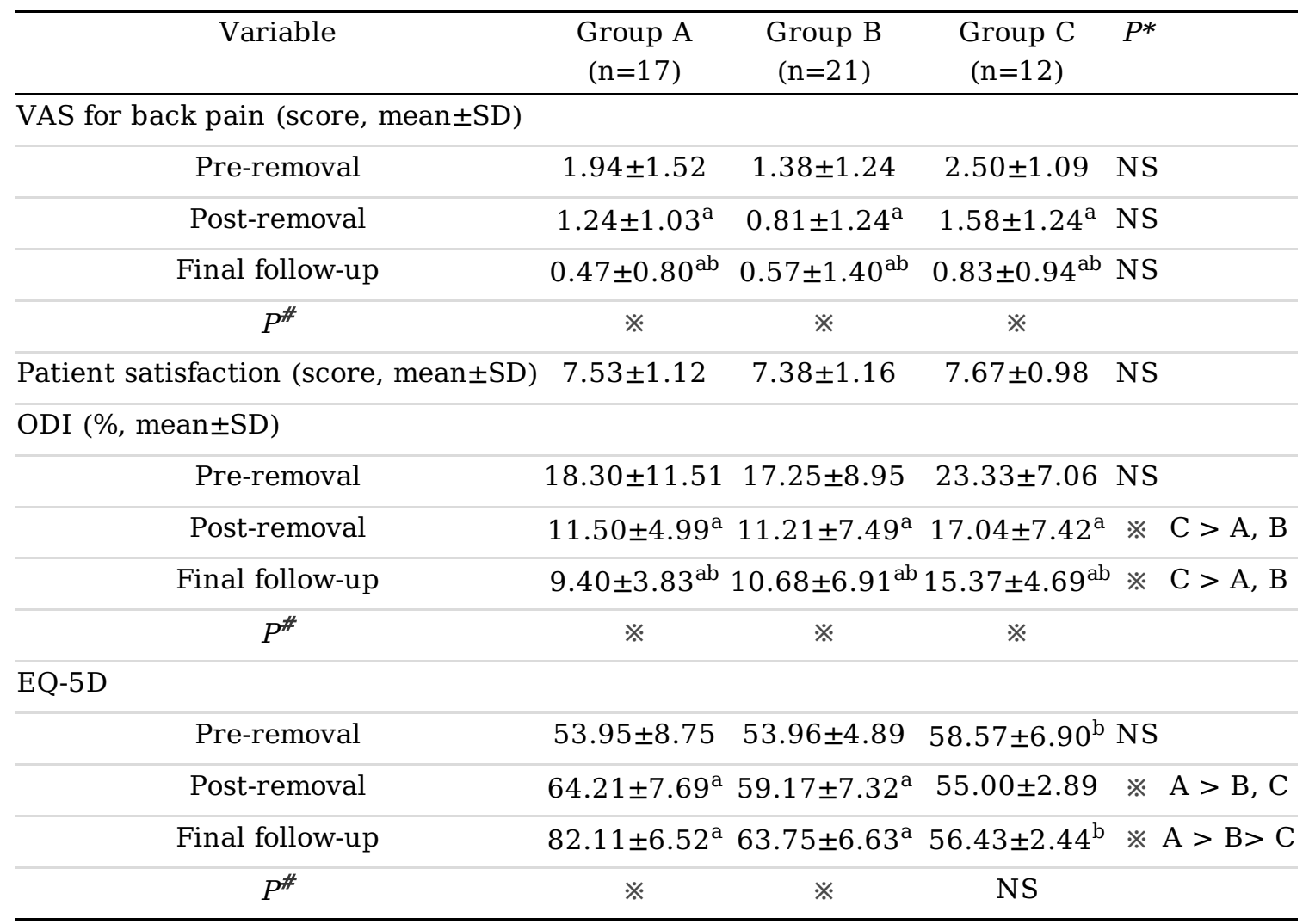

$\mathrm{P}^{*}$ were calculated using one-way ANOVA among three groups and LSD between groups.

$P \#$ were calculated using repeated analysis among three groups.

Compared to "Pre-removal", a $P<0.05$; Compared to "Post-removal", b $P>0.05$.

$※, P<0.05$.

Table 3. ROM of Involved Segments at Final Follow-up

\begin{tabular}{|c|c|c|c|c|}
\hline Variable & $\begin{array}{c}\text { Group A } \\
(n=17)\end{array}$ & $\begin{array}{c}\text { Group B } \\
(n=21)\end{array}$ & $\begin{array}{c}\text { Group C } \\
(\mathrm{n}=12)\end{array}$ & $P$ \\
\hline Total $\left({ }^{\circ}\right)$ & $\begin{array}{c}11.5 \pm 6.2 \\
\text { (5.4 to } 32.3)\end{array}$ & $\begin{array}{c}5.5 \pm 1.6 \\
(2.7 \text { to } 8.6)\end{array}$ & $\begin{array}{c}2.4 \pm 0.6 \\
(1.8 \text { to } 4.1)\end{array}$ & $※ A>B>C$ \\
\hline Per segment $\left({ }^{\circ}\right)$ & $\begin{array}{c}5.8 \pm 3.1 \\
(2.7 \text { to } 16.1)\end{array}$ & $\begin{array}{c}2.5 \pm 0.9 \\
(0.7 \text { to } 4.3)\end{array}$ & $\begin{array}{c}1.2 \pm 0.4 \\
(0.6 \text { to } 2.0)\end{array}$ & $※ \mathrm{~A}>\mathrm{B}>\mathrm{C}$ \\
\hline$\%$ of normal values & $\begin{array}{c}41.6 \pm 13.0 \\
(25.6 \text { to } 65.3)\end{array}$ & $\begin{array}{c}18.4 \pm 5.9 \\
\text { (7.1 to } 29.6)\end{array}$ & $\begin{array}{c}8.8 \pm 3.3 \\
(5.2 \text { to } 17.0)\end{array}$ & $※ A>B>C$ \\
\hline
\end{tabular}

$P$ were calculated using one-way ANOVA among three groups and LSD between groups.

$※, P<0.05$.

\section{Figures}




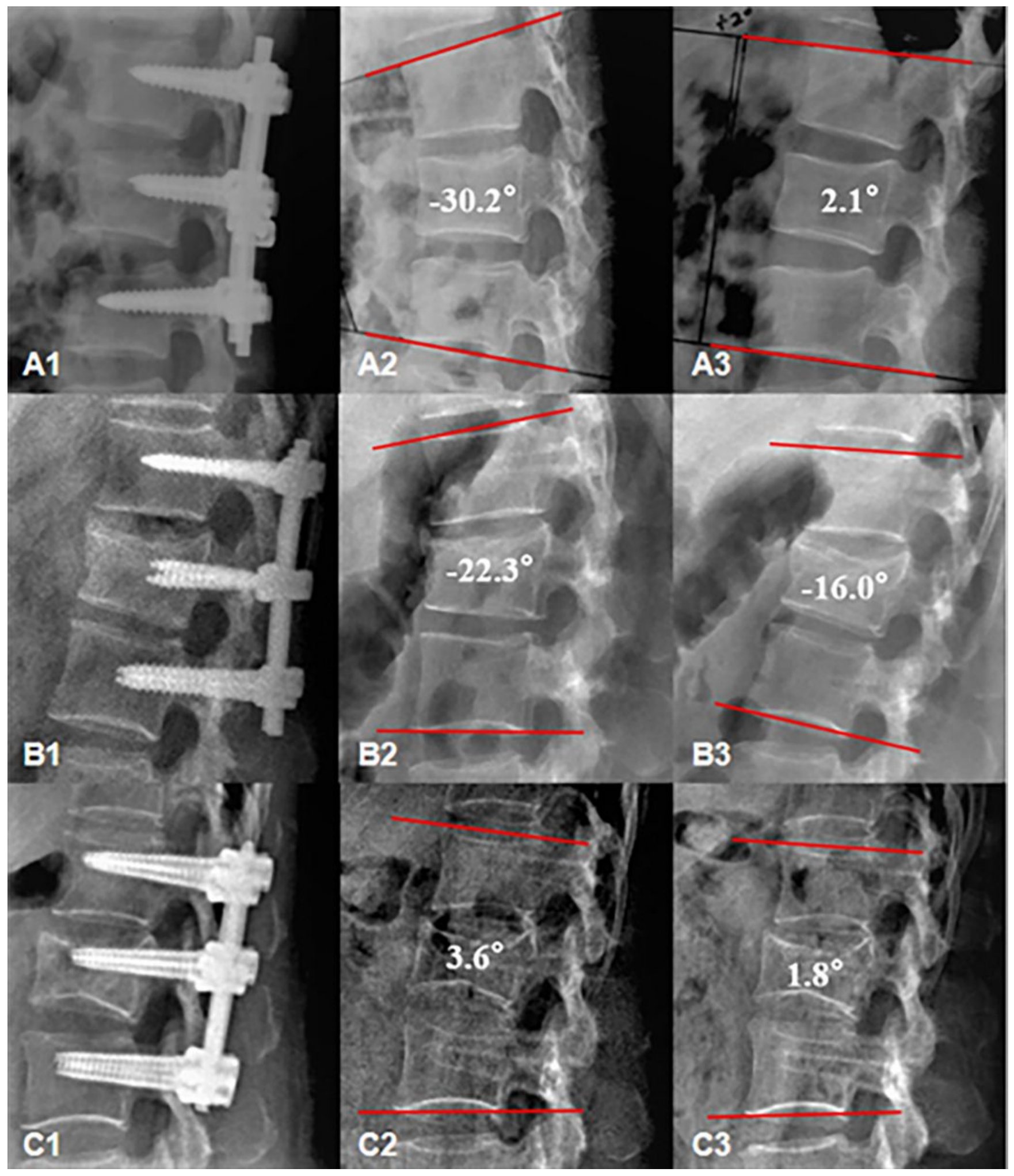

\section{Figure 1}

Patients with thoracolumbar and lumbar fractures underwent implant removal at different times following posterior fixation surgery without fusion. A. A 45-year-old male had a burst fracture at L2 with implant removal after 9 months. (A1) Anteroposterior radiograph obtained at 1 week after fixation surgery; $(A 2, A 3)$ Flexion-extension lateral radiograph obtained at 3 months after implant removal, Cobb angle were $-30^{\circ}$ and $2^{\circ}$, segmental ROM was $32^{\circ}$. B. A 41 -year-old male had a burst fracture at $L 3$ with 
implant removal after 13.5 months. (B1) Anteroposterior radiograph obtained at 1 week after fixation surgery; (B2, B3) Flexion-extension lateral radiograph obtained at 3 months after implant removal, Cobb angle were $-22.3^{\circ}$ and $-16.0^{\circ}$, segmental ROM was $6.3^{\circ}$. C. A 43-year-old female had a burst fracture at L2 with implant removal after 24.1 months. (C1) Anteroposterior radiograph obtained at 1 week after fixation surgery; $(\mathrm{C} 2, \mathrm{C} 3)$ Flexion-extension lateral radiograph obtained at 2 months after implant removal, Cobb angle were $3.6^{\circ}$ and $1.8^{\circ}$, segmental ROM was $1.8^{\circ}$.

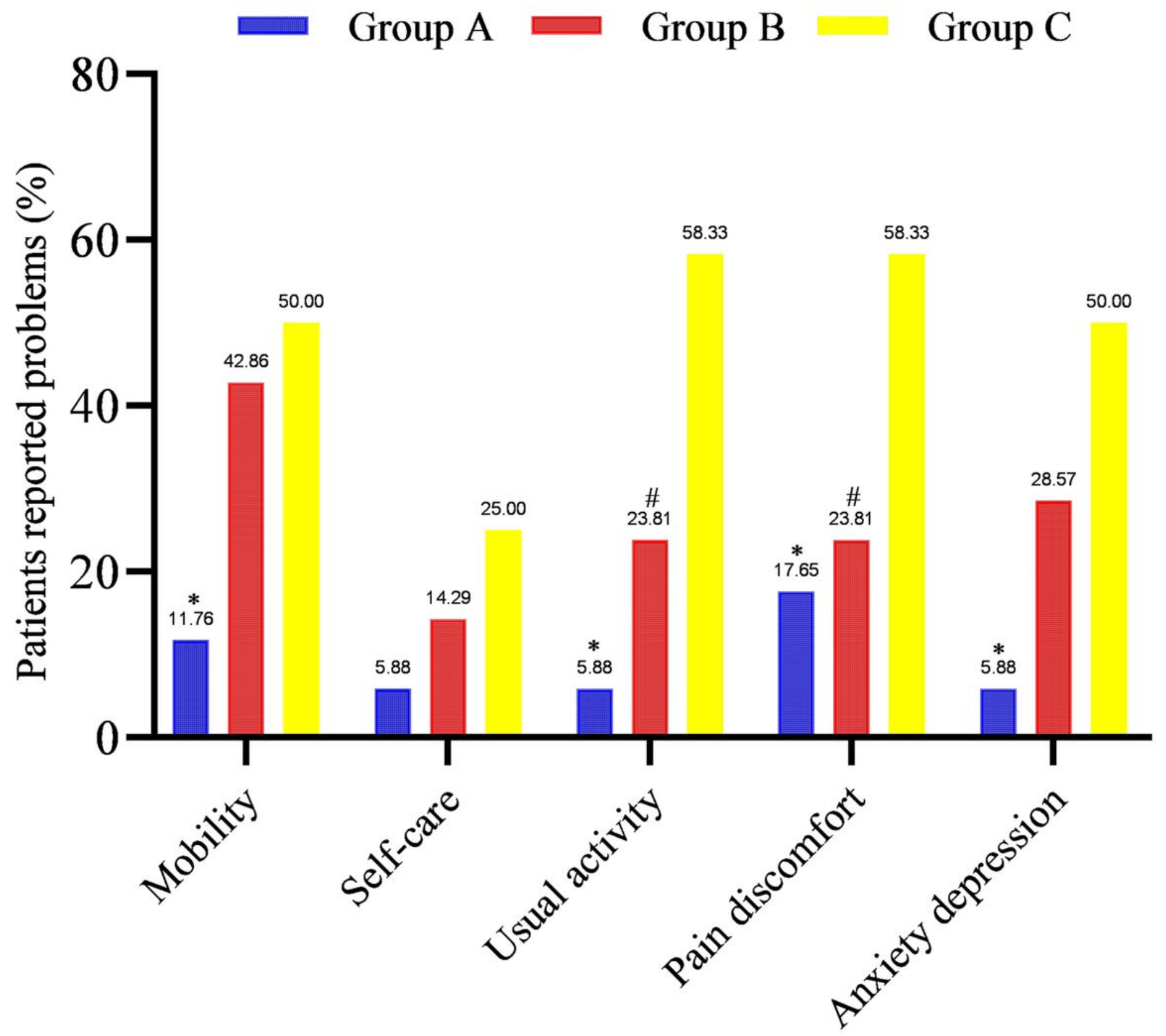

Figure 2

Proportions of patients that reported problems on the different EQ-5D domains among three groups at final follow-up. Group A showed the lowest proportion of patients that reported problems in all domains except for self-care. Compared to group $B$ and $C$, ${ }^{*} P<0.05$; Compared to group $C, \# P<0.05$. 